Original article

\title{
Influence of electromagnetic environment of mobile communication devices on incidence of cardiovascular diseases
}

\author{
Svetlana G. Yashchenko, Sergey Yu. Rybalko, Sergey E. Shibanov \\ V.I. Vernadsky Crimean Federal University, Simferopol, Russia
}

Received 3 August 2018, Revised 3 October 2018, Accepted 13 October 2018

(C) 2018, Yashchenko S.G., Rybalko S.Yu., Shibanov S.E.

(C) 2018, Russian Open Medical Journal

\begin{abstract}
The aim of this work was the monitoring of electromagnetic environment generated by mobile communication terminals (MCTs) in the places of their active operation for identifying statistical relationships between incidence of cardiovascular diseases (CVD) and results of this monitoring.

Material and Methods - To assess the electromagnetic environment the energy flow density (EFD) of MCTs was determined by the PZ-34 electromagnetic flow meter. Medical-statistical analysis of CVD was carried out using the data from statistical reports. Pearson correlation coefficient and Kendall rank correlation coefficient were calculated.

Results - The electromagnetic environment was monitored at 472 points, and the values of EFD were within range of $0.82 \pm 0.02 \mu W / \mathrm{cm}^{2}$ to $2.09 \pm 0.12 \mu \mathrm{W} / \mathrm{cm}^{2}$. Significant positive correlation was found between average values of EFD and overall incidence of CVD (Tau=0.411, $\mathrm{p}=0.01$ ).

Conclusion - Monitoring of electromagnetic environment created by MCTs revealed that the average value of EFD was $1.35 \pm 0.07 \mu \mathrm{W} / \mathrm{cm}^{2}$. We have found a statistically significant correlation between the mean values of EFD and overall incidence of CVD, among individual CVD there was a highly significant positive correlation with ischemic heart disease incidence, and there was a positive correlation with average values of CVD incidence growth rate.
\end{abstract}

Keywords: cardiovascular system, disease, monitoring, electromagnetic radiation, mobile communication.

Cite as Yashchenko SG, Rybalko SYu, Shibanov SE. Influence of electromagnetic environment of mobile communication devices on incidence of cardiovascular diseases. Russian Open Medical Journal 2018; 7: e0410.

Correspondence to Svetlana G. Yashchenko. E-mail: yswet.net@mail.ru.

\section{Introduction}

There is evidence of influence of radiofrequency (RF) electromagnetic radiation (EMR) on non-carcinogenic risks for public health [1]. Experimental studies have shown that RF EMR affects laboratory animals [2-4]. On several occasions [5] areas with elevated risk of adverse influence on health of mobile communication users were identified, ecological situation and possible risks for public health due to environmental contamination by electromagnetic fields of mobile communication base stations were evaluated [6]. Issues of modeling electromagnetic field (EMF) levels with $300 \mathrm{HHz}-300 \mathrm{MHz}$ frequency generated by radiotransmitters, radiolocation systems and mobile communication in a large regional center are being studied [7], new methods of background EMR intensity evaluation are being developed [8]. Generally, all studies confirm the relevance of further research for determining influence of electromagnetic fields and radiation (EMFaR) on human organism; it is shown that hazards associated with this factor are underestimated, and that there is no systemic approach to EMFaR evaluation [7]. Impact of RF EMR on cardiovascular system (CVS) becomes a specific subject of research: moderate bradycardia was registered in adult volunteers in response to $0.9 \mathrm{HHz}$ frequency EMR exposure [9], shifts in regulation of human circulatory system were found [10].

Increasing incidence of cardiovascular diseases (CVD) in Russia urges implementation of effective long-term nationwide prevention measures [11]. Studies of CVD epidemiology in different climatic and geographical areas are promising from scientific point of view [12]. According to data provided by Russian Federation Ministry of Health [13], in 2014 in Crimea there were significantly more registered cases of cerebrovascular diseases (CeVD), ischemic heart disease (IHD) and diseases associated with elevated blood pressure (BP) than in Russia on average $(40.23 \%$ higher to over 2.5 times higher).

As such, impact of RF EMR on CVS, distinct difference in CVD incidence and morbidity between Crimea and Russia overall, along with active reconstruction of mobile communication network in this region has allowed us to set the aim for this study: monitoring of electromagnetic environment generated by mobile communication terminals (MCTs) at sites of their active exploitation to detect statistical relationship between its results and CVD incidence. 
Table 1. Rates of overall and primary CVD morbidity in Crimean population (per 100 thousand people)

\begin{tabular}{lcccc}
\hline Condition & & Year & & Average GR \\
& 2015 & 2016 & 2017 & \\
\hline OM CVD & 51,878 & 48,603 & 47,243 & 0.91 \\
PM CVD & 4,356 & 2,960 & 2,780 & 0.64 \\
OM IHD & 20,740 & 20,094 & 18,994 & 0.92 \\
PM IHD & 1,538 & 937 & 876 & 0.57 \\
OM EBP & 19,748 & 18,718 & 17,814 & 0.90 \\
PM EBP & 1,187 & 688 & 690 & 0.58 \\
OM CeVD & 6,676 & 6,099 & 6,002 & 0.89 \\
PM CeVD & 952 & 809 & 774 & 0.81 \\
\hline
\end{tabular}

$\mathrm{GR}$, growth rate; $\mathrm{OM}$, overall morbidity rate; $\mathrm{PM}$, primary morbidity rate; CVD, cardiovascular diseases; IHD, ischemic heart disease; EBP, diseases with elevated blood pressure; CeVD, cerebrovascular diseases.

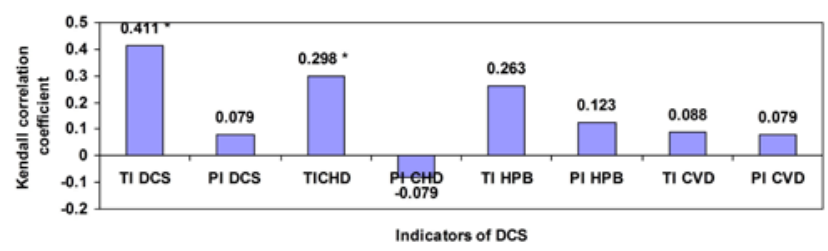

Figure 1. Correlation between EFD and CVD rates. * $-\mathrm{P}<0.05$.

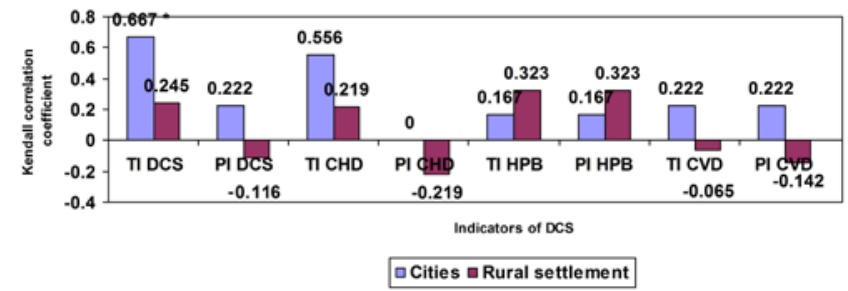

Figure 2. Correlation relationship between EFD and CVD rates in towns and villages. ${ }^{*}-\mathrm{P}<0.05$.

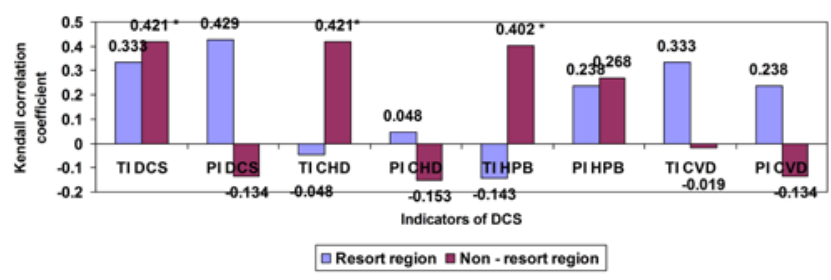

Figure 3. Correlation relationship between EFD and CVD rates in resort and non-resort areas. ${ }^{*}-\mathrm{P}<0.05$.

\section{Material and Methods}

\section{Methods of electromagnetic environment evaluation}

To perform a hygienic evaluation of RF electromagnetic environment in Republic of Crimea we used the method of measuring levels of EMR generated by MCTs without taking electromagnetic background generated by other RF sources into account [5]. Parameters of radiation were measured in areas of their active exploitation by mobile phone users (town microdistricts, towns and villages). Number of measurement sites in territorial units of Republic of Crimea varied between 3 and 60 depending on their area.
EMR level of MCT was determined using electromagnetic meter PZ-34 with AP 3-34 microwave antenna (NTM Zaschita Inc., Moscow, Russia). At every measurement site EMR level was determined sequentially for two identical MCTs (Samsung G3) with SIM cards of two leading (in Republic of Crimea) mobile operators ("Win Mobile" and "Volna") used in voice mode (2G network) to speak with remote user. Radiation level was determined by energy flow density (EFD) three times at $1.7 \mathrm{~m}$ height and 0.37 distance between MCT and PZ-34 antenna with background level below 0.3 $\mu \mathrm{W} / \mathrm{cm}^{2}$.

\section{Methods of CVD morbidity evaluation}

Medical statistical analysis of primary and overall CVD morbidity in Republic of Crimea in 2015-2017 was performed on basis of statistical reports received from state institution "Crimean Medical Informational-Analytical Center". Among all CVD we identified diseases associated with elevated BP (ICD-10: 110-115), IHD (ICD-10: 120-125) and CeVD (ICD-10: 170-179) as the most common conditions (around 90\% in total) of all CVD. Due to the fact that statistical reports were given on 22 administrative units of Republic of Crimea, we combined towns of Dzhankoy, Krasnoperekopsk and Saki with their corresponding districts.

\section{Statistical analysis}

Variational series of data were checked for normality of distribution using Kolmogorov-Smirnov test, series with normal distribution were checked for relationship using Pearson correlation analysis, series with non-normal distribution were checked using Kendall rank correlation coefficient.

\section{Results}

After processing data acquired in 2015-2017 on overall and primary morbidity for all CVD and for specific nosological entities in 22 districts of Republic of Crimea, we calculated their mean values (Table 1) and average overall incidence growth rates (GR).

It should be noted that for all CVD and for specific conditions we have found a trend toward decrease in overall morbidity during three years included in our analysis. Average GR were within range of $0.57-0.91$.

Next step was to determine electromagnetic environment in Crimean regions, and those results are shown in Table 2.

EFD measurements were performed at 472 sites, and EFD values obtained were within range of $0.82 \pm 0.02 \mu \mathrm{W} / \mathrm{cm}^{2}$ to $2.09 \pm 0.12 \mu \mathrm{W} / \mathrm{cm}^{2}$, average EVD value for Crimea was $1.35 \pm 0.07 \mu \mathrm{W} / \mathrm{cm}^{2}$, which doesn't exceed threshold of $3 \mu \mathrm{W} / \mathrm{cm}^{2}$, established in Russian Federation [14]. The study allowed to determine regions with high EFD (compared to average value in Crimea), which are, first of all, Pervomayskiy $\left(2.09 \pm 0.12 \mu \mathrm{W} / \mathrm{cm}^{2}\right)$, Chernomorskiy $\left(1.91 \pm 0.07 \mu \mathrm{W} / \mathrm{cm}^{2}\right)$ and Krasnogvardeyskiy districts $\left(1.79 \pm 0.08 \mu \mathrm{W} / \mathrm{cm}^{2}\right)$, as well as town of Simferopol $\left(1.95 \pm 0.04 \mu \mathrm{W} / \mathrm{cm}^{2}\right)$. Lowest values of EFD were determined in Armyansk $\left(0.97 \pm 0.07 \mu \mathrm{W} / \mathrm{cm}^{2}\right)$, Kerch $\left(0.94 \pm 0.04 \mu \mathrm{W} / \mathrm{cm}^{2}\right)$ and Feodosia $\left(1.05 \pm 0.03 \mu \mathrm{W} / \mathrm{cm}^{2}\right)$.

Then we calculated Kendall correlation coefficient for relationship between EFD and main characteristics of CVD incidence, which included overall morbidity rate (OM) per 100 thousand people and primary morbidity rate (PM) per 100 thousand people (Figure 1). 


\begin{tabular}{|c|c|c|c|c|c|c|}
\hline \multirow[t]{2}{*}{ № } & \multirow[t]{2}{*}{ A.u. } & \multicolumn{4}{|c|}{ OM, per 100,000 people } & \multirow[t]{2}{*}{$E F D, W / \mathrm{cm}^{2}$} \\
\hline & & CVD & IHD & $\mathrm{EBP}$ & CeVD & \\
\hline 1 & Simferopol & $52,120 \pm 844$ & $23090 \pm 146,7$ & $17270 \pm 200$ & $8584 \pm 274$ & $1.95 \pm 0.04$ \\
\hline 2 & Yevpatoria & $47190 \pm 3896$ & $19940 \pm 1284$ & $21080 \pm 2689$ & $3707 \pm 506$ & $1.23 \pm 0.05$ \\
\hline 3 & Feodosia & $42190 \pm 664$ & $19970 \pm 177$ & $12630 \pm 472$ & $7796 \pm 309$ & $1.05 \pm 0.03$ \\
\hline 4 & Kerch & $33120 \pm 4514$ & $15460 \pm 2519$ & $11880 \pm 1818$ & $2907 \pm 567$ & $0.94 \pm 0.04$ \\
\hline 5 & Yalta & $56050 \pm 827$ & $17840 \pm 385$ & $19100 \pm 1632$ & $6214 \pm 443$ & $1.31 \pm 0.06$ \\
\hline 6 & Alushta & $73480 \pm 891$ & $29680 \pm 269$ & $8621 \pm 257$ & $4251 \pm 96$ & $1.41 \pm 0.11$ \\
\hline 7 & Armyansk & $37270 \pm 1464$ & $18280 \pm 689$ & $14280 \pm 1099$ & $2716 \pm 439$ & $0.97 \pm 0.07$ \\
\hline 8 & Sudak & $36100 \pm 2590$ & $12570 \pm 1844$ & $21660 \pm 1117$ & $1350 \pm 284$ & $1.21 \pm 0.07$ \\
\hline 9 & Krasnoperekopsk & $57050 \pm 1309$ & $22840 \pm 671$ & $29360 \pm 804$ & $2735 \pm 189$ & $1.71 \pm 0.12$ \\
\hline 10 & Bahchisarayskiy district & $56280 \pm 883$ & $18270 \pm 201$ & $24750 \pm 506$ & $11680 \pm 284$ & $1.11 \pm 0.04$ \\
\hline 11 & Belogorskiy district & $17250 \pm 183$ & $7095 \pm 240$ & $4620 \pm 218$ & $3416 \pm 167$ & $0.82 \pm 0.02$ \\
\hline 12 & Dzhankoyskiy district & $34750 \pm 1387$ & $16180 \pm 187$ & $12280 \pm 1201$ & $2813 \pm 302$ & $1.17 \pm 0.09$ \\
\hline 13 & Kirovskiy district & $30230 \pm 1136$ & $16870 \pm 2662$ & $6248 \pm 355$ & $3779 \pm 908$ & $1.09 \pm 0.07$ \\
\hline 14 & Krasnogvardeyskiy district & $79970 \pm 1730$ & $32930 \pm 616$ & $39310 \pm 927$ & $5908 \pm 179$ & $1.79 \pm 0.08$ \\
\hline 15 & Leninskiy district & $48130 \pm 1717$ & $12950 \pm 282$ & $23450 \pm 919$ & $10330 \pm 525$ & $1.41 \pm 0.05$ \\
\hline 16 & Nizhnegorskiy district & 277302596 & $16420 \pm 2298$ & $6470 \pm 493$ & $1741 \pm 240$ & $1.31 \pm 0.03$ \\
\hline 17 & Pervomayskiy district & $46660 \pm 999$ & $24030 \pm 1160$ & $18580 \pm 415$ & $1736 \pm 253$ & $2.09 \pm 0.12$ \\
\hline 18 & Razdolnenskiy district & $50800 \pm 2423$ & $14270 \pm 283$ & $22390 \pm 1879$ & $12200 \pm 567$ & $1.23 \pm 0.04$ \\
\hline 19 & Sakskiy district & $80570 \pm 1737$ & $24210 \pm 1791$ & $43190 \pm 190$ & $9320 \pm 319$ & $1.52 \pm 0.08$ \\
\hline 20 & Simferopolskiy district & $48270 \pm 2394$ & $22080 \pm 780,4$ & $18020 \pm 759$ & $4283 \pm 392$ & $1.24 \pm 0.06$ \\
\hline 21 & Sovetskiy district & $50470 \pm 3525$ & $18490 \pm 2036$ & $12000 \pm 620$ & $17820 \pm 1874$ & $1.23 \pm 0.03$ \\
\hline 22 & Chernomorskiy district & $29870 \pm 916$ & $9541 \pm 253$ & $10790 \pm 474$ & $6898 \pm 315$ & $1.91 \pm 0.07$ \\
\hline
\end{tabular}

Data presented as mean with error of mean $-M \pm m$.

A.u., administrative units of Republic of Crimea; OM, overall morbidity rates; CVD, cardiovascular diseases; IHD, ischemic heart disease; EBP, diseases with elevated blood pressure; CeVD, cerebrovascular diseases.

We found positive and significant correlation relationship between average values of EFD and overall morbidity rates for all CVDs (Tau=0.411, $p=0.01$ ) and IHD OM (Tau=0.298, $p=0.04$ ). Statistical analysis of correlation relationships between EFD and GR has demonstrated a significant positive Pearson correlation between EFD and CVD OM ( $R=0.512, p=0.02)$.

Correlation significance check using Kendall test with stratification of CVD morbidity rates by urbanization (town or village) (Figure 2) allowed to obtain following correlation coefficients: between average values of EFD and overall morbidity rates in towns (items 1-9, Table 2) - CVD (Tau=0.667, $\mathrm{p}=0.03$ ). In village areas we found this relationship (items 10-22, Table 2) for primarily diagnosed IHD (Tau $=0.539, p=0.03$ ). A similar check of correlation relationship with stratification between resort areas (items 2, 3, 5, 6, 8, 19, 22, Table 2) and non-resort areas (Figure 3) demonstrated correlation coefficients for relationship between EFD and overall morbidity rates in non-resort areas for CVD (Tau=0.421, $p=0.02)$, IHD (Tau=0.429, $p=0.02)$, elevated BP ( $\mathrm{Tau}=0.402, p=0.03)$; EFD and GR IHD (Tau $=0.643, p=0.03)$, as well as for EFD and GR EBP (Tau $=0.643, p=0.03$ ) in resort areas.

\section{Discussion}

Analysis of overall CVD morbidity rates and morbidity of individual CVDs shows that first place there belongs to IHD (40.5\%), second - to EBP (38.1\%), and third - to CeVD (12.7\%), which is in concordance with general morbidity rates in Russian Federation [13]. Main indicators of dynamics of studied conditions - average GR for 2015-2017 - were significant; overall CVD morbidity in Crimea lowered by $9 \%$, IHD morbidity lowered by $8 \%$, elevated BP - by $10 \%$, and CeVD - by $11 \%$, which demonstrates efficacy of preventive measures. GR PM for these conditions has shown decrease by $36,43,42$ and $19 \% \%$, respectively.
This study allowed to identify village areas and towns of Crimea with high EFD. In village regions it is determined by a small mobile communication base station (BS) density and increased distance between terminal and BS, which is in concordance with literature [8]. Relatively high EFD value in Simferopol is explained by high BS workload and high electromagnetic background, created by other sources of RF radiation. Minimal values of EFD in Armyansk, Kerch and Feodosia may be explained by "saturation" of these areas by BSs and their relatively low workload. This distribution of EFD for areas with low and high urbanization is typical for this type of studies [15].

Positive correlation between EFD and all CVDs we detected, as well as with OM of IHD, allows us to introduce a hypothesis on possible action of RF EMF of mobile communication terminals on functional status of CVS with consequent development of CVD, which is in accord with literature data [16-18]. Results we obtained when stratifying data on the principle of urbanization are concordant with the literature [5] and strengthen the hypothesis of electromagnetic environment influence on incidence of CVD. Results of dividing data by resort and non-resort areas may imply that seasonal workload may influence EBP in population of resort areas and require further research.

\section{Conclusions}

Statistically significant correlation relationships between EFD and CVD OM were found. Among the components of CVD we found significant positive correlation with IHD OM and with GR CVD OM.

We found significant correlation relationships between EFD and CVD OM in towns, and between EFD and IHD GR in villages, which was found for the first time. We also found significant correlation coefficients in non-resort areas between EFD and CVD, 
$I H D$, EBP OM, between EFD and IHD GR; and in resort areas between EFD and EBP OM GR.

\section{Limitations}

Limitations of this study able to decrease accuracy of assessment of EFD impact on CVD are of multiple origin; specifically, we didn't take into account population density, migration, seasonal migration, other cardiovascular risk factors, which were not discussed in this article. Moreover, limitations of this study are caused by strict formalization of statistical reports by Ministry of Health of Republic of Crimea.

\section{Ethical approval}

Study of this type doesn't require approval of an ethics committee.

\section{Funding}

This research was supported by Russian Foundation for Basic Research, Grant № 18-013-01028A.

\section{Conflict of interest}

Authors have no conflict of interest to disclose.

\section{References}

1. Grigoriev YuG, Samoylov AS, Bushmanov AYu, Khorseva NI. Cellular connection and the health of children - problem of the third millennium. Medical Radiology and Radiation Safety (Mosc) 2017; 62(2): 39-46. Russian. https://elibrary.ru/item.asp?id=29374874.

2. Aydogan F, Aydin E, Koca G, Ozgur E, Atilla P, Tuzuner A, et al. The effects of $2100-\mathrm{MHz}$ radiofrequency radiation on nasal mucosa and mucociliary clearance in rats. Int Forum Allergy Rhinol 2015; 5: 626632. https://dx.doi.org/10.1016/j.amjoto.2014.10.001.

3. Bakacak M, Bostanci MS, Attar R, Yildirim OK, Yildirim G, Bakacak Z, et al. The effects of electromagnetic fields on the number of ovarian primordial follicles: An experimental study. Kaohsiung J Med Sci 2015; 31: 287-292. https://dx.doi.org/10.1016/j.kjms.2015.03.004.

4. Yashchenko SG, Rybalko SYu. Morphological structure of rat epiphysis exposed to electromagnetic radiation from communication devices. Gig Sanit 2016; 95(10): 977-979. Russian. https://www.ncbi.nlm.nih.gov/pubmed/29431353.

5. Pchelnik OA, Nefedov PV. Electromagnetic fields of cell phones and health risk to users. Fundamental Research 2014; 10(10): 1971-1975. Russian. https://elibrary.ru/item.asp?id=22970086.

6. Movchan VN, Shmakov IA. About the influence of the cellular base stations on the ecological situation in a large city. Mezhdunarodnyj Zhurnal Prikladnyh i Fundamental'nyh Issledovanij 2016; 5(3): 426428. Russian. https://elibrary.ru/item.asp?id=25911009.

7. May IV, Balashov SYu, Vekovshinina SA, Kudrya MA. On assessing electromagnetic field $(300 \mathrm{KMHz}-300 \mathrm{MHz})$ in a large industrial city on the basic of 3D modeling and instrumental measuring. Health Risk Analysis 2017; (3): 21-30. Russian. https://elibrary.ru/item.asp?id=30069959.

8. Mordachev VI. Verification of the worst case model for the estimation of average intensity of the electromagnetic background created by base stations of cellular communications. Doklady BGUIR 2018; (1): 12-18. Russian. https://elibrary.ru/item.asp?id=32491356.

9. Grigoriev YuG, Grigoriev OA. Cellular communication and health. Electromagnetic environment. Radiobiological and hygienic problems. The prognosis of hazard. Moscow, Russia: Economica, 2013: 164-199. Russian. https://elibrary.ru/item.asp?id=21134182.

10. Gurkovskiy BV, Murtazina EP, Zhuravlev BV, Gridneva NA, Trifonova $N Y$, Simakov $A B$. Changes in the heart rate variability of human during passing of tests under exposure to electromagnetic fields of $900 \mathrm{MHz}$
GSM band. Biomedical Radioelectronics 2015; (4): 30-32. Russian. https://elibrary.ru/item.asp?id=23835807.

11. Oganov RG, Maslennikova GYa. Demographic trends in the Russian federation: the impact of cardiovascular disease. International Heart and Vascular Disease Journal 2013; 1(1): 3-10. Russian. https://elibrary.ru/item.asp?id=28392140.

12. Boytsov SA, Oganov RG. From preventive cardiology to non-communicable disease prevention in Russia. Russian Journal of Cardiology 2013; (4): 6-13. Russian. https://elibrary.ru/item.asp?id=20260468.

13. The general morbidity of the adult population of Russia in 2014. Statistical data. P. IV. Moscow, Russia, 2015: 69 - 81. Russian. https://www.rosminzdrav.ru/documents/9479.

14. SanPiN 2.1.8/2.2.4.1190-03. Hygienic requirements for deployment and operation of land mobile radio communication facilities. Sanitary rules and norms. Moscow, Russia: Federal'nyj centr Gossanepidnadzora Minzdrava Rossii, 2003. Russian.

15. Urbinello D, Joseph W, Verloock L, Martens L, Röösli M. Temporal trends of radio-frequency electromagnetic field (RF-EMF) exposure in everyday environments across European cities. Environ Res 2014; 134 : 134-142. https://dx.doi.org/10.1016/j.envres.2014.07.003.

16. Vangelova K, Deyanov C, Israel M. Cardiovascular risk in operators under radiofrequency electromagnetic radiation. Int J Environ Health 2006; 209(2): 133-38. https://doi.org/10.1016/j.ijheh.2005.09.008.

17. Bortkiewicz A, Gadzicka E, Szymczak W, Zmyslov M. Heard rate variability (HRV) analysis in radio and TV broadcasting stations workers. Int J Occup Med Environ Health 2012; 25(4): 446-455. https://dx.doi.org/10.2478/s13382-012-0059-x.

18. Ekici B, Tanindi A, Ekici G, Diker E. The effects of the duration of mobile phone use on heart rate variability parameters in healthy subjects. Anatol J Cardiol 2016; 11: 833-838. https://dx.doi.org10.14744/AnatolJCardiol.2016.6717.

\section{Authors:}

Svetlana G. Yashchenko - MD, PhD, Assistant Professor, Department of General Hygiene with Ecology, V.I. Vernadsky Crimean Federal University, Simferopol, Russia. http://orcid.org/0000-0001-6817-8639.

Sergey Yu. Rybalko - PhD, Assistant Professor, Department of Medical Physics and Informatics, V.I. Vernadsky Crimean Federal University, Simferopol, Russia. http://orcid.org/0000-0002-3809-4992.

Sergey E. Shibanov - MD, DSc, Professor, Head of Department of General Hygiene with Ecology, V.I. Vernadsky Crimean Federal University, Simferopol, Russia. http://orcid.org/0000-0002-9322-5836. 